\title{
Study of Tribological and Thermal Properties of Engine Lubricant by Dispersion of Aluminium Nano Additives
}

\author{
Bachina Harish $\mathrm{Babu}^{1 *}$, Dillip Kumar Sahoo ${ }^{2}$ \\ ${ }^{1}$ Department of Automobile Engineering, Vignan's Foundation for Science, Technology \& Research (Deemed to be University), \\ Vadlamudi 522213, India \\ ${ }^{2}$ School of Mechanical Engineering, Sathyabama Institute of Science \& Technology, Chennai 600119, India
}

Corresponding Author Email: bhb_ae@vignan.ac.in

https://doi.org/10.18280/rcma.300207

Received: 12 December 2019

Accepted: 26 February 2020

\section{Keywords:}

aluminium and aluminium oxide nano particles, nano lubricants, frictional force, thermal conductivity, viscosity

\begin{abstract}
This study is experimental investigation of the tribological and thermal properties of aluminium and aluminium oxide nano particles immersed in engine lubricating oil. SAE20W40SL oil was used as base oil in which aluminium and aluminium oxide nano particles in size of $50 \mathrm{~nm}$ at the concentration of $0.2 \%$ and $0.1 \%$ were disseminated. Ultrasonic bath was used for the dispersal of the nano particles in the base oil. Pin-OnDisk apparatus was used for the measurement of the frictional force and wear rate of the lubricant. The results indicated a reduction in frictional force by $52 \%$ and $28 \%$ by aluminium and aluminium oxide nano lubricants at $0.2 \%$ concentration. The thermal conductivity test result showed an increase in thermal conductivity by $4.8 \%$ and $2.3 \%$ while using aluminium and aluminium oxide lubricants at $0.2 \%$ concentration. A reduction in the wear rate and viscosity of the lubricants was also seen while using nano particles.
\end{abstract}

\section{INTRODUCTION}

In Automotive engine, research on nano fluid lubricants are gaining more interest due to enhancement of its tribological performance, oil properties, exhaust emission, and heat transfer rate. Present days, due to its size, shape and other chemical properties, nanoparticles have appeared as a new kind of additive in lubricants. A nano lubricant is a new kind of engineering lubricant made of nanoparticles, dispersant, and base lubricant. Material performance exploitation nanoparticles already has appreciable achievements within the past decades. Nanoparticles (nano-additives) added to the operating fluid to create nanofluids that are wide accustomed enhance the thermal physical phenomenon, heat transfer performance, and tribological properties of the operating fluid [1]. In recent years, many scientists, researchers have added different nanoparticles in to the engine lubricant to develop a nano film which can improve the tribological properties of lubricant and boost the operative potency and life time of machinery parts.

The nano-additives in nano-lubricants comprise numerous metal compound nanoparticles $\left(\mathrm{CuO}, \mathrm{TiO}_{2}\right.$, and $\left.\mathrm{ZnO}\right)$, metal nanoparticles $(\mathrm{Cu}, \mathrm{Al})$ non-metal/metal compound nanoparticles (graphite, boric acid, diamond). Majority of the literature showed that due to its shape and size of nano additives, the engine lubricants will decrease the coefficient of friction, power losses, wear and improve the wear resistance and tribological performance of machinery. Additionally, nano-additives have high thermal conduction which will enhance the heat transfer caused by mechanical friction. Hence addition of nanoparticles into the lubricating oil can boost the mechanical properties. several studies also showed that the viscosity of lubricants was increased with increase in concentration of nanoparticles. Howbeit, the impact of nanoparticle concentration on increasing viscussness of nanooils is gradually reduced by increasing nano-oil temperature [2]. Experimental results with nanoparticles used as additives in oil lubricants showed that they deposited on the friction surfaces and improve the tribological properties of the lubricating oil, displaying sensible friction and wear reduction options even at low concentrations [3]. Titanic oxide $\left(\mathrm{TiO}_{2}\right)$ nanoparticles as lubricator additive were studied with more attention, attributable to their sensible performance on antioxidant options, comparatively low toxicity, pleasant odour, and non-volatility [4]. Due to the shape, size and other distinctive properties, nanoparticles and nanotubes have also emerged and grown as a new kind of additive for engine lubricants. In actuality, nano-lubricants are made from nanostructures, dispersants and base lubricants which exhibits a new kind of engineering lubricants and improving the lubricating effect and thermal conductivity properties compared to basic lubricants $[5,6]$. The nano lubricant additives in automotive engine to improve the tribological performance, oil properties, exhaust emission, combustion, saving of fuels and enhance heat transfer rate [7]. Many scientists, researchers have been investigated various properties of nano lubricants like anti-wear, anti-frictional, formation of protective film, rolling effect on friction surfaces by considering different nanoparticles such as fullerene, titanium dioxide, copper oxide, nano-diamond and so on with different shape and structures [8-14]. Additionally, properties like thermal conductivity, corrosion resistance has been 
studied for nano particles with spherical and tubular structures added with single walled and multi walled carbon nano tubes. Howbeit, limited published article has been seen on investigating nano lubricants properties like viscosity, flash point, fire point and pour point in both theoretical and experimental approaches [15].

\section{MATERIALS AND METHODOLOGY}

\subsection{Materials}

The aluminium and aluminium oxide nano materials are used as additive and the average size of the nano particles are $50 \mathrm{~nm}$. The average size of the nano material used is $45 \mathrm{~nm}$. The weight concentrations of the aluminium and aluminium oxide nano particles are $0.2 \%$ and $0.1 \%$ of base oil respectively. The specification of base oil SAE $20 \mathrm{~W} 40$ are shown in Table 1.

Table 1. Properties of SAE $20 \mathrm{~W} 40$

\begin{tabular}{|c|c|}
\hline Thermal conductivity & $0.180 \mathrm{w} / \mathrm{m}-\mathrm{k}$ \\
\hline Density & $2.375 \mathrm{~g} / \mathrm{cm}^{3}$ \\
\hline Kinematic viscosity @ 100 c & $13.5-15.5$ \\
\hline Viscosity index & 133 \\
\hline Flash point & $2000 \mathrm{C}$ \\
\hline Pour point & $210 \mathrm{C}$ \\
\hline
\end{tabular}

\subsection{Preparation of nano lubricants}

The productiveness of the nano lubricant depends on its rate of dissolution and stability with respect to temperature. If the stability is not satisfactory then the nano materials tend to agglomerate with each other and degrade the performance of the nano lubricant. In this experimental work the aluminium and aluminium oxide nano particles are dispersed to the base lubricant by the help of bath type ultrasonicator. The dispersed nano particles are in terms of weight fraction and the concentration level are $0.2 \%$ and $0.1 \%$ of base lubricant weight. The requisite weight of the aluminium and aluminium oxide nano particles corresponding to the mass fraction was precisely measured using a high accuracy electronic balance and kept in the sonicator for 1 hour as sonication period. The prepared nano lubricants are kept under supervision for more than 36 hours to prepare a stable suspension and then various properties are measured. Properties of metallic aluminium and aluminium oxide are shown in Table 2.

\subsection{Experimental set up}

For conducting experimental study, a single cylinder, water cooled, four stroke DI Compression Ignition engine with a displacement volume of $661 \mathrm{cc}$, developing $60.2 \mathrm{KW}$ at 1800 rpm was used (Displayed in Figure 1). Different load tests area unit conducted for a ranging from no load, $0.8,16,24$ to 32 $\mathrm{kW}$ power output at a constant rated speed of $1500 \mathrm{rpm}$, with fuel injection pressure of 200 bars and cooling water exit temperature at $60^{\circ} \mathrm{C}$. The governor of the engine was accustomed manage the engine speed. The engine had a combustion chamber with overhead valves operated through push rods. Cooling of the engine was accomplished by activity water through the jackets on the cylinder block and cylinder head. A piezoelectric pressure transducer was used to measure the cylinder pressure and located on cylinder head by suitable arrangement. Additionally, the engine was coupled with eddy current dynamometer and can withstand high pressure encountered during tests.

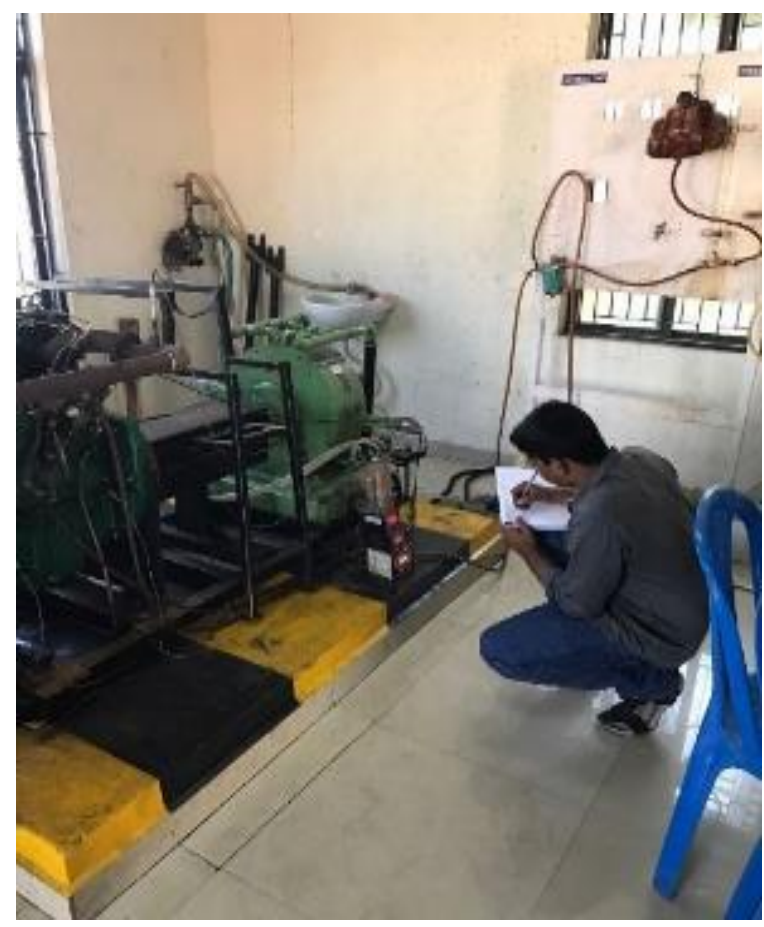

Figure 1. Experimental engine set up

\subsection{The pin on disk tester}

The Frictional Force was measured using the Pin-on-Disk apparatus. A static aluminium pin and rotating Grey Cast Iron test samples was prepared according to ASTM G99 standards. These test samples actually mimic the piston and liner surface in the engine. In this test arrangement, Normal load of $30 \mathrm{~N}$ was applied on the pin which was held vertically against the rotating disc at a radial distance of $30 \mathrm{~mm}$. The sliding distance taken for this test was $1000 \mathrm{~mm}$ and the rotational speed of the disc was fixed at $1250 \mathrm{rpm}$. The Frictional force generated between the pin and rotating disc was due to the applied load which was indicated by a Tribology Data Acquisition system. During the test, the base oil and nano lubricant was introduced between the rotating disk and pin, in drops, at a constant flow rate of $0.15 \mathrm{~L}$ per hour. The Frictional Force was recorded for a period of $8 \mathrm{~min}$, the average value was noted for each concentration of aluminium and aluminium oxide nano particles.

Table 2. Properties of aluminium nano particles

\begin{tabular}{ccccccc}
\hline Item & Purity & APS & SSA & Colour & Morphology & Density \\
\hline Aluminium nanoparticles & $99.99 \%$ & $50 \mathrm{~nm}$ & $20 \mathrm{~m}^{2} / \mathrm{g}$ & Dark Grey & Spherical & $2.7 \mathrm{~g} / \mathrm{cm}^{3}$ \\
Aluminium oxide nanoparticles & $99.2 \%$ & $40 \mathrm{~nm}$ & $58 \mathrm{~m}^{2} / \mathrm{g}$ & White Powder & Nearly Spherical & $2.0 \mathrm{~g} / \mathrm{cm}^{3}$ \\
\hline
\end{tabular}




\section{RESULTS AND DISCUSSION}

\subsection{Frictional force}

The frictional forces were measured by Pin on disc apparatus under controlled room temperature of $32^{\circ} \mathrm{C}$. The development of frictional forces between the pin and disc are shown in Table 3. It has been seen that the aluminium nano lubricants with $0.2 \mathrm{wt} \%$ concentration offering low frictional force compared to other nano lubricants and base lubricants. By considering frictional force the coefficient of friction was calculated and plotted in Figure 2. The coefficient of friction is minimum at $\mathrm{Al} 0.2 \mathrm{wt} \%$ nano lubricants and maximum at base lubricants. The reason for the decrease in coefficient of friction is due to the part load is carried by metallic aluminium nano particles during formation. So, the optimum concentration for the nano lubricant can be taken as $0.2 \%$. for minimizing frictional coefficients.

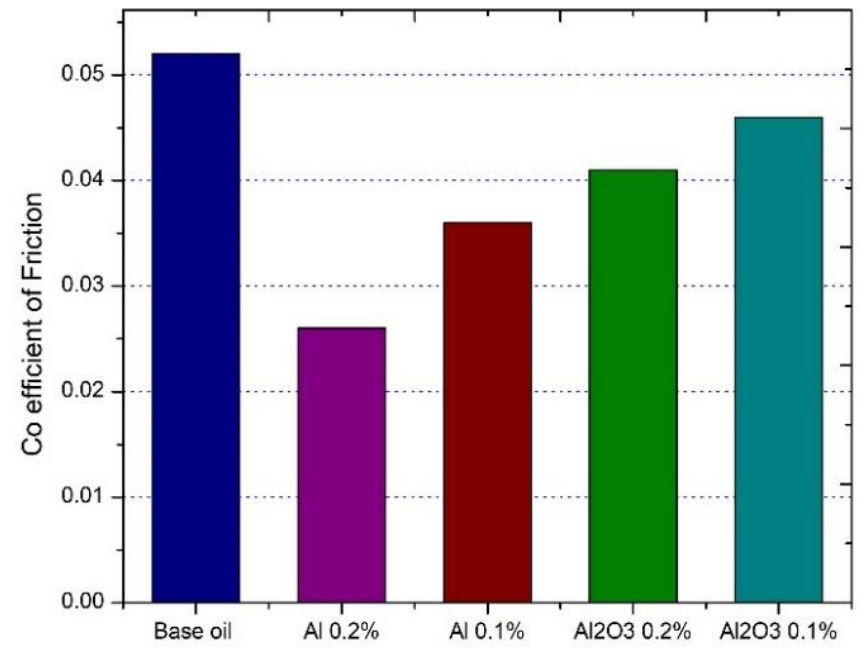

Figure 2. Coefficient of friction for different nano lubricants

Table 3. Frictional force generated for various types of lubricants

\begin{tabular}{cccc}
\hline Type of lubricant & $\begin{array}{c}\text { Normal } \\
\text { load (N) }\end{array}$ & $\begin{array}{c}\text { Average } \\
\text { frictional } \\
\text { force (N) }\end{array}$ & $\begin{array}{c}\text { Friction } \\
\text { coefficient }\end{array}$ \\
\hline Base lubricants & 30 & 1.68 & 0.052 \\
$\mathrm{Al} 0.2 \%$ & 30 & 0.69 & 0.026 \\
$\mathrm{Al} 0.01 \%$ & 30 & 1.28 & 0.048 \\
$\mathrm{Al}_{2} \mathrm{O}_{3} 0.2 \%$ & 30 & 1.18 & 0.041 \\
$\mathrm{Al}_{2} \mathrm{O}_{3} 0.1 \%$ & 30 & 1.44 & 0.046 \\
\hline
\end{tabular}

Figure 3 shows the frictional force generated between the pin and rotating disc with respect to time. At the beginning of the experiment the friction force generated is very high due to the direct contact of the pin and disc. By the introduction of nano lubricants Frictional forces decreases gradually with respect to time and it was due to the formation of nano lubricants thin films between the pin and disc surface, simultaneously some part load was carried by metallic nano particles. By adding the aluminium and aluminium oxide nano particles in the lubricant the frictional forces reduced by $52 \%$ and $28 \%$ with $0.2 \%$ concentrations similarly $40 \%$ and $19 \%$ with $0.1 \%$ concentrations.

Adding the aluminium and aluminium oxide nano particles in lubricant reduce the frictional force at higher rate than the conventional lubricants. The aluminium nano materials will melt under high temperature and forms the thin film between two moving components and thin soft film will provide a very smooth surface and also carry away some of the applied load and reduce the frictional force. Comparing with the aluminium oxide nano particles, the metallic aluminium shows better results in terms of frictional force and frictional coefficients.

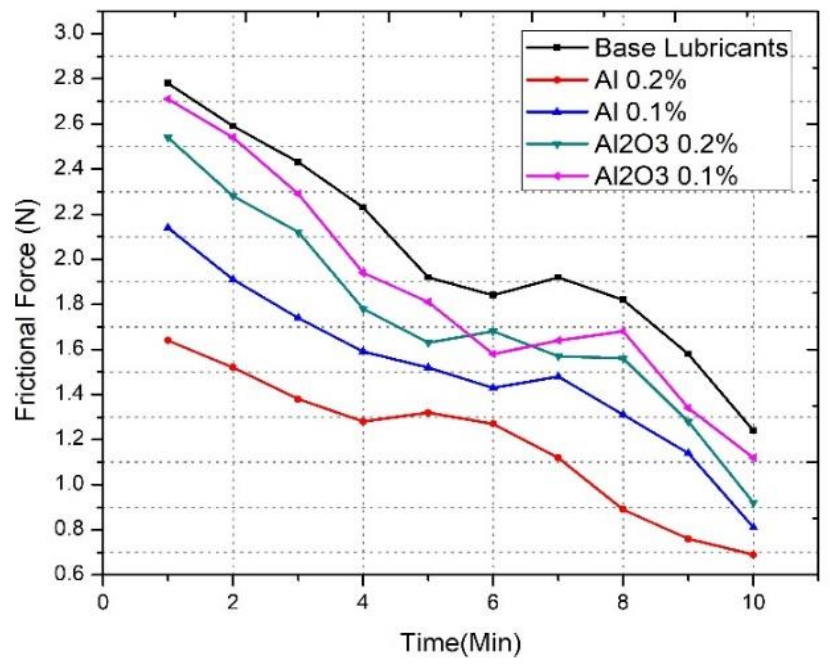

Figure 3. Frictional force Vs time for different nano lubricants

\subsection{Wear rate}

The wear rate has been calculated on static aluminium pin before and after friction measurement. A very high precision weighing machine was used to take the measurements and much attention was given as the weight change is very less. The results are shown in Figure 4 and noticed that the wear rate is high for conventional lubricants compared to nano lubricants. By adding aluminium and aluminium oxide nano particles the wear rate reduced by $61 \%$ \& $38 \%$ in $0.2 \%$ concentration and by $48 \%$ \& $23 \%$ in $0.1 \%$ concentration respectively. At high temperature the nano particles will melted and form a thin film which will prevent the direct contact between frictional surfaces and reduce the wear rate considerably.

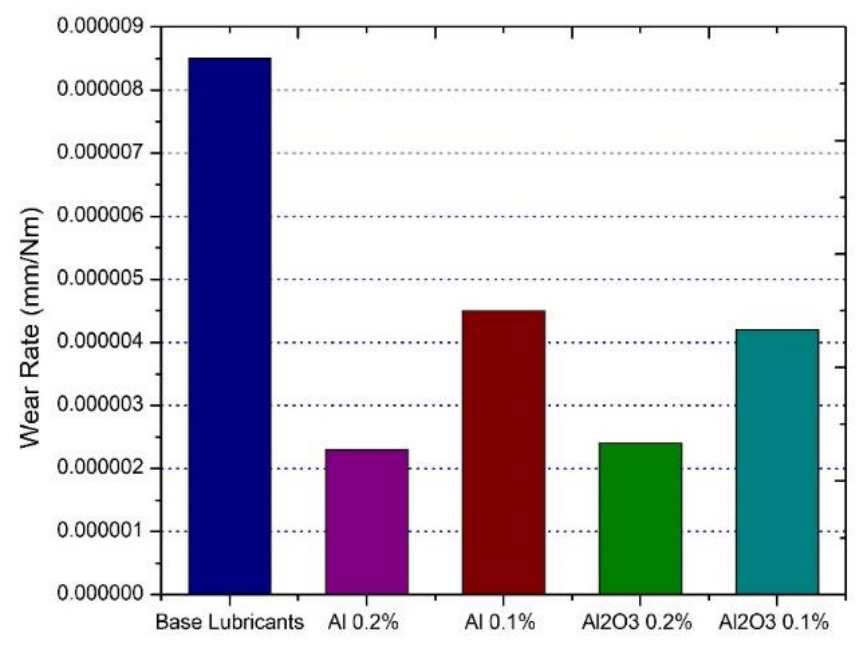

Figure 4. Wear rate of base and nano lubricants 


\subsection{Thermal conductivity}

KD2-Pro instrument was used to measure the thermal conductivity of the base and nano lubricants (Displayed Figure 5). The instrument used the transient hot wire system to measure the thermal conductivity of the lubricants and the results are shown in Figure 6. Result shows the thermal conductivity of the Nano lubricant is higher than the base lubricant. Since the nano materials are very small in size so the surface area per unit volume increases which influence to increase the conductivity. In addition to that the effect of Brownian motion which increases as the nano materials size decreases, which also help to improve the thermal conductivity. From the results the Thermal Conductivity increases about $4.8 \%$ and $2.3 \%$ for metallic aluminium and aluminium oxide nano lubricants with $0.2 \%$ concentration and $1.8 \% \& 1.2 \%$ for aluminium and aluminium oxide nano lubricants with $0.1 \%$ concentrations respectively. Increase in thermal conductivity increases the heat conduction property of engine lubricant which makes the nano lubricants suitable for high temperature application.

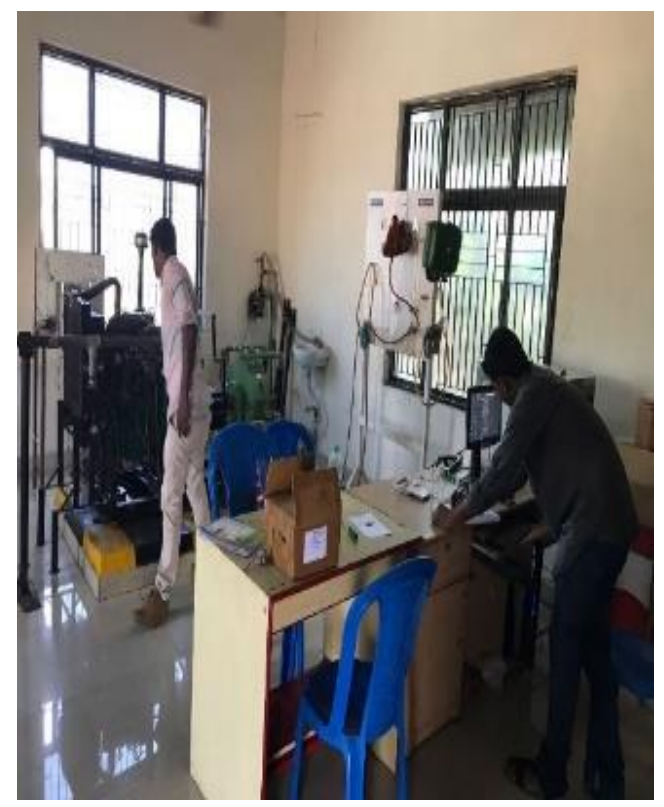

Figure 5. Thermal conductivity testing set up

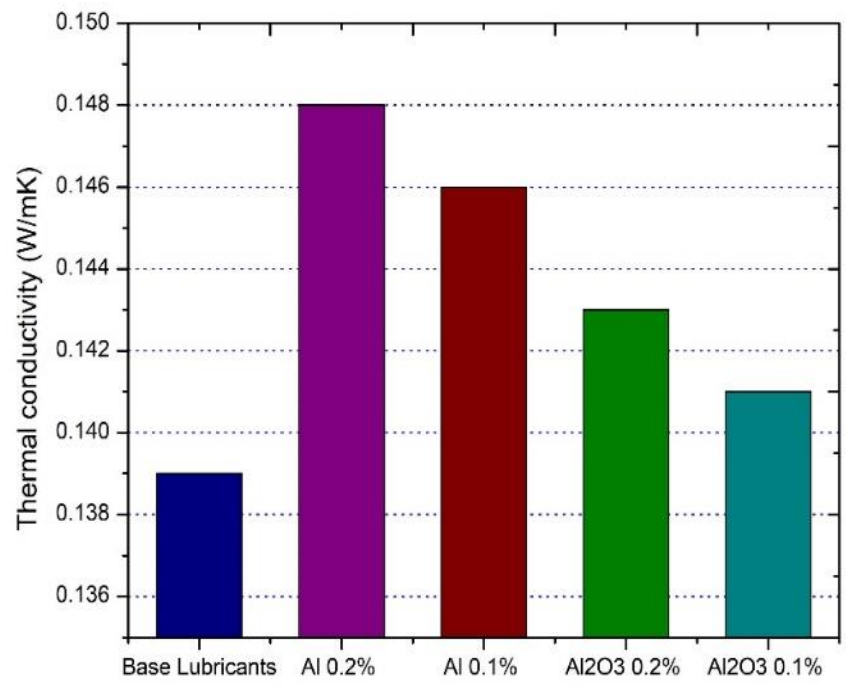

Figure 6. Thermal conductivity of base and nano lubricants

\subsection{Kinematic viscosity}

Redwood viscometer was used to measure the kinematic viscosity of both base and nano lubricants. Sample of $50 \mathrm{~mL}$ of lubricants was filled in the vertical cylindrical chamber and maintained by a constant temperature bath. The results of kinematic viscosity of both base and nano lubricants are shown in Figure 7. The results indicate that the kinematic viscosity gradually decreases with increase in temperature. The kinematic viscosity decreases about $20 \%$ and $12 \%$ in case of metallic aluminium and aluminium oxide nano lubricants with $0.2 \%$ concentration and $16 \% \& 12 \%$ for aluminium and aluminium oxide nano lubricants with $0.1 \%$ concentrations respectively. Increase the viscosity of the lubricants will improve the heat transfer rate and enhance the thermal conductivity during operation.

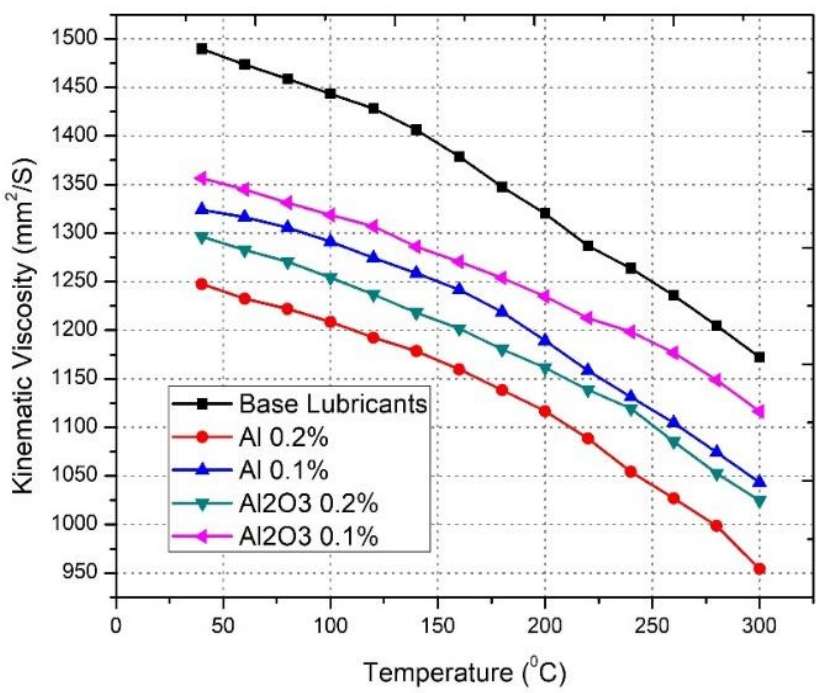

Figure 7. Kinematic viscosity of base and nano lubricants

\section{CONCLUSION}

The aluminium and aluminium oxide nano particles were added as an additive to SAE $20 \mathrm{~W} 40$ lubricant oil at $0.2 \mathrm{wt} \%$ and $0.01 \mathrm{wt} \%$ concentrations. The properties like frictional force, Frictional coefficient, wear rate, Thermal conductivity and Kinematic Viscosity were evaluated between base lubricants and nano lubricants and following conclusions were made.

* Adding the aluminium and aluminium oxide nano particles in the base lubricant the frictional forces reduced by $52 \%$ and $28 \%$ with $0.2 \%$ concentrations similarly reduced by $40 \%$ and $19 \%$ with $0.1 \%$ concentrations.

* Aluminium and aluminium oxide nano particles reduced the wear rate by $61 \% \& 38 \%$ in $0.2 \%$ concentration and by $48 \%$ \& $23 \%$ in $0.1 \%$ concentrations.

* Thermal Conductivity increases about $4.8 \%$ and $2.3 \%$ for metallic aluminium and aluminium oxide nano lubricants with $0.2 \%$ concentration and $1.8 \% \& 1.2 \%$ for nano lubricants with $0.1 \%$ concentrations respectively.

* The kinematic viscosity decreases about $20 \%$ and $12 \%$ in case of metallic aluminium and aluminium oxide nano lubricants with $0.2 \%$ concentration and $16 \% \& 12 \%$ for nano lubricants with $0.1 \%$ concentrations respectively. 
By evaluating the above properties, it can be suggested that lubricants with $0.2 \mathrm{wt} \%$ of metallic aluminium nano additives be the optimum concentration for improving the properties of the engine lubricants compared to lubricants with $0.1 \mathrm{wt} \%$ concentration.

\section{REFERENCES}

[1] Kittelson, D.B. (1998). Engines and Nano Particles: A Review. Journal of Aerosol Science, 29(5-6): 575-588. https://doi.org/10.1016/S0021-8502(97)10037-4

[2] Hudson, L.K., Eastoe, J., Dowding, P.J. (2006). Nanotechnology in action: Overbased nanodetergents as lubricant oil additives. Advances in Colloid and Interface Science, 123-126: 425-431. https://doi.org/10.1016/j.cis.2006.05.003

[3] Zhmud, B., Pasalskiy, B. (2013). Nano materials in lubricants: An industrial Perspective current research. Lubricants, 1: 95-101. https://doi.org/10.3390/lubricants 1040095

[4] Ilie, F., Covaliu, C. (2016). Tribological properties of the lubricant containing titanium dioxide nanoparticles as an $\begin{array}{lll}\text { Additive. } & \text { Lubricants, } & \text { 4(2): }\end{array}$ https://doi.org/10.3390/lubricants4020012

[5] Wan, Q.M., Jin, Y., Sun, P.C., Ding, Y.L. (2015). Tribological behaviour of a lubricant oil containing boron nitride nanoparticles. Procedia Engineering, 102: 1038-1045.

https://doi.org/10.1016/j.proeng.2015.01.226

[6] Pisal, A.S., Chavan, D.S. (2014). Experimental investigation of tribological properties of engine oil with $\mathrm{CuO}$ nanoparticles. International Journal on Theoretical and Applied Research in Mechanical Engineering, 3(2): 34-38.

[7] Laad, M., Jatti, V.K.S. (2018). Titanium oxide nanoparticles as additives in engine oil. Journal of King Saud University - Engineering Sciences, 30(2): 116-112. https://doi.org/10.1016/j.jksues.2016.01.008

[8] Asrula, M., Zulkiflia, N.W.M., Masjukia, H.H., Kalama,
M.A. (2013). Tribological properties and lubricant mechanism of nanoparticle in engine oil. Procedia Engineering, $\quad 68: \quad 320-325$ https://doi.org/10.1016/j.proeng.2013.12.186

[9] Mohan, N., Sharma, M., Singh, D., Gandra, N. (2014). Tribological properties of automotive lubricants SAE 20W-40 containing nano $\mathrm{Al}_{2} \mathrm{O}_{3}$ particles. SAE Technical Paper, SAE 2014 International Powertrain, Fuels \& Lubricants Meeting. https://doi.org/10.4271/2014-012781

[10] Akl, S., Abdel-Rehim, A., Khafagy, E. (2016). Tribological properties of engine lubricant with nanocopper oxide as an additive. SAE Technical Paper, SAE 2016 World Congress and Exhibition. https://doi.org/10.4271/2016-01-0487

[11] Thottackkad, M.V., Perikinalil, R.K., Kumarapillai, P.N. (2012). Experimental evaluation on the tribological properties of coconut oil by the addition of $\mathrm{CuO}$ nanoparticles. International Journal of Precision Engineering and Manufacturing, 13(1): 111-116. https://doi.org/10.1007/s12541-012-0015-5

[12] Choi, C., Jung, M., Choi, Y., Lee, J., Oh, J. (2011). Tribological properties of lubricating oil-based nanofluids with metal/carbon nanoparticles. Journal of Nanoscience and Nanotechnology, 11(1): 368-371. https://doi.org/10.1016/j.wear.2009.12.023

[13] Vadiraj, A., Manivasagam, G., Kamani, K., Sreenivasan, V.S. (2012). Effect of nano oil additive proportions on friction and wear performance of automotive materials. Tribology in Industry, 34(1): 3-10. https://doi.org/tribology.rs/journals/2012/2012-1/1

[14] Zin, V., Agresti, F., Barison, S., Colla, L., Gondolini, A., Fabrizio, M. (2013). The synthesis and effect of copper nanoparticles on the tribological properties of lubricant oils. IEEE Transactions on Nanotechnology, 12(5): 751759. https://doi.org/10.1109/TNANO.2013.2273566

[15] Wu, Y.Y., Tsui, W.C., Liu, T.C. (2007). Experimental analysis of tribological properties of lubricating oils with nanoparticle additives. Wear, 262(7-8): 819-825. https://doi.org/10.1016/j.wear.2006.08.021 